\title{
FACTORS AFFECTING ACTIVE CONSTITUENTS OF SAFFRON (CROCUS SATIVUS L.)
}

\author{
Mila Arapcheska ${ }^{1 *}$, Jovanka Tuteska $^{2}$ \\ 1 “St. Kliment Ohridski” University, Faculty of Biotechnical Sciences, Bitola, \\ R. of North Macedonia \\ 2 "St. Kliment Ohridski" University, High Medical School, - Bitola, \\ R. of North Macedonia
}

\begin{abstract}
Saffron (Crocus sativus L) is a plant with high economical and medicinal value. The dried and dark-red stigmas of flowers of Crocus sativus L., is the most expensive spice in the world. Saffron is used mainly as a spice for flavouring and coloring of food, but also numerous pharmacological studies have indicated its therapeutic potential including antioxidant, anticancer, antiischemic, hypolipidemic, antitussive, antidepressive, sedative and antiinflammatory effects. Saffron contains more than 150 volatiles and aroma-yielding compounds, and many non-volatile active components (such as: zeaxanthin, lycopene, and various $\alpha$ - and $\beta$-carotenes). Three main pharmacologically active metabolites: crocins; picrocrocin and safranal are responsible for the colour, taste and aroma of saffron. The quantities of secondary metabolites are influenced by many factors. Agronomic and environmental factors can affect the morphological and anatomical features of the plants as well as quantity of secondary metabolites. However, the most considerable influence on chemical composition of saffron has a post-harvest processing. The dehydration treatment necessary to convert Crocus sativus L. stigmas into saffron spice is one of the most important factors. Different treatments used for draying stigma have different impact on secondary metabolite contents, and they determine stability, quality, and economical value of the saffron.
\end{abstract}

Keywords: bioactive components, postharvest processing, saffron

\section{INTRODUCTION}

Crocus sativus L. is a plant with high economical and medicinal value. It is a member of the family Iridaceae. From its flower stigmas is obtained most expensive spice in the world - saffron, which is among the highest priced high value agricultural products in the world. Saffron refers to the dried and dark-red stigmas of flowers of $C$. sativus. Also, it is named "the red gold", and because of its color, flavor, and aroma it is very appreciated. The word "saffron" is derived from the Arabic word "zafran", which means "yellow" (Abdullaev and Frenkel, 1999; Caballero-Ortega et al., 2004; Husaini et al., 2006; Bagur et al., 2018). As a result of the specific glycosidic constituents saffron possesses powerful coloring and flavoring properties, and it plays an important role in the culinary culture of different regions in the world, were it used as food additive. Also, saffron is used in traditional medicine in the treatment of various kinds of illnesses by various civilizations (Caballero-Ortega et al., 2004; Bathaie and Mousavi, 2010). 
C. sativus. is a sterile triploid plant that is naturally propagated vegetatively by corms. Flowers emerge in autumn. The outstanding feature of the $C$. sativus flower is its three stigmas, $25-30 \mathrm{~mm}$ long, which droop over the petals, that is what is collected as saffron. There are also three yellow stamens, which lack the active compounds and are not collected. The stigma is attached to a style (Fig. 1), which has little of the active components and is only included with the lower grades of saffron (Wani et al., 2011).

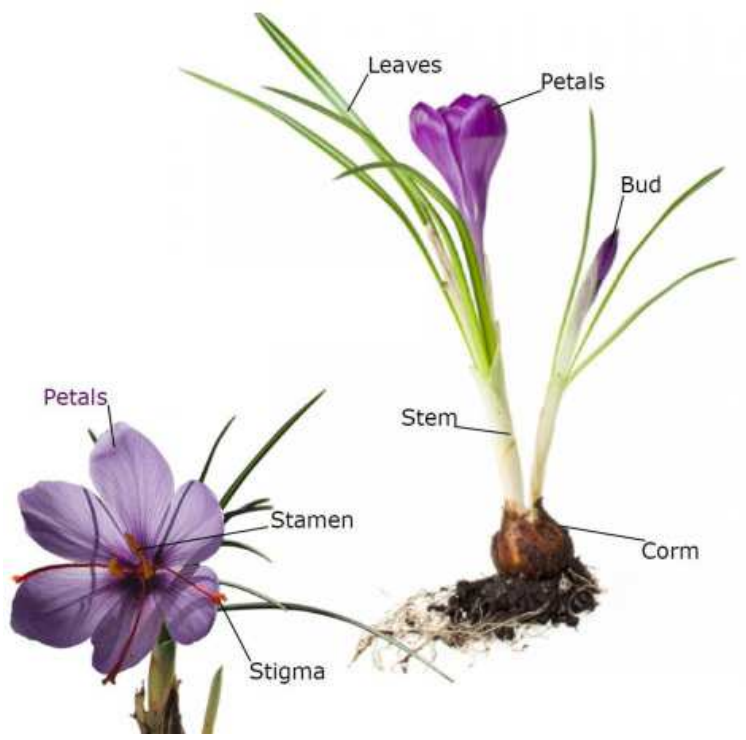

Figure 1. Crocus sativus L. plant morphology (https://rainbowpeacockco.wordpress.com/on-saffron)

The use of saffron date back to ancient Egypt and Rome, where it was used as a dye in perfume and as a spice for culinary purposes as well as in treatment of different diseases (Abdullaev, 2007). In the Ebers papyrus (1550 BC) saffron is mentioned as an ingredient for a cure of kidney problems. Hippocrates, Theophrastus and Galen considered saffron to be an appetite stimulant, which can help in the relief of digestive disorders and has calming effects on infants (Velasco-Negueruela, 2001). $C$. sativus red stigmas contain a number of secondary chemical derivatives, which have been used for treatment of different health conditions. Many of health properties of saffron have been scientifically confirmed. Various pharmacological studies have been described that saffron and its constituents exhibit different beneficial properties, including antioxidant, anticancer, anticonvulsant, antiischemic, antigenotoxic, antidote, antiapoptotic, antitussive, antidepressive, sedative and hypnotic, hypolipidemic, antihypertensive, antinociceptive and antiinflammatory effect (Wani et al., 2011; Rahimi, 2015;). Saffron also improves memory and learning skills and increases blood flow in the retina and choroid. The antioxidant activity has been hypothesized to be one of the important mechanisms for the various pharmacological effects of saffron (Srivastava et al., 2010; Tong et al., 2015).

Also, saffron has attracted a renewed interest for its use in cosmetics. Since ancient times, saffron is used for cosmetic purposes. Cleopatra used it in her beauty products. In traditional Greek medicine, it can refresh the skin of the face and is used to relieve the liver of the domination of bile and to treat acne, skin diseases and wounds. Also, saffron tepals have been studied in several studies as being rich in crocin and kaempferol, thus representing an important source of bioactive compounds for potential cosmetic formulations (Mzabri et., 2019). 


\section{SAFFRON BIOACTIVE COMPOUNDS}

In view of wide range of medical uses, phytochemical and biochemical analysises of saffron bioactive compounds are subject of numerous studies and variety of biologically active ingredients has been isolated.

Saffron contains more than 150 volatile and aroma-yielding compounds. It also has many nonvolatile active components, many of which are carotenoids including zeaxanthin, lycopene, and various $\alpha$ - and $\beta$-carotenes. The volatiles with a very strong odor are consistent of more than 34 components that are mainly terpenes, terpene alcohols, and their esters. Non-volatiles include crocins (monoglycosyl polene esters of crocetine) saffron-colored compounds, responsible for the red or reddish brown color of stigmas together with carotenes, crocetin - natural apocarotenoid dicarboxylic acid and precursor of crocin, picrocrocin (glycosidic precursor of safranal), responsible of the bitter taste in saffron and safranal the major organoleptic principle of stigmas responsible of the characteristic saffron aroma (Fig. 2). By subjecting picrocrocin to hydrolysis and dehydration, safranal, is obtained. Also, saffron contains proteins, sugars, vitamins, flavonoids, amino acids, mineral matter, gums, and other chemical compounds. Presence of biologically active compaunds such as crocetin, picrocrocin and safranal make this spice promising candidate for functional food (Abdullaev, 2007; Srivastava et al., 2010; Jan et al., 2014; Rahimi, 2015).
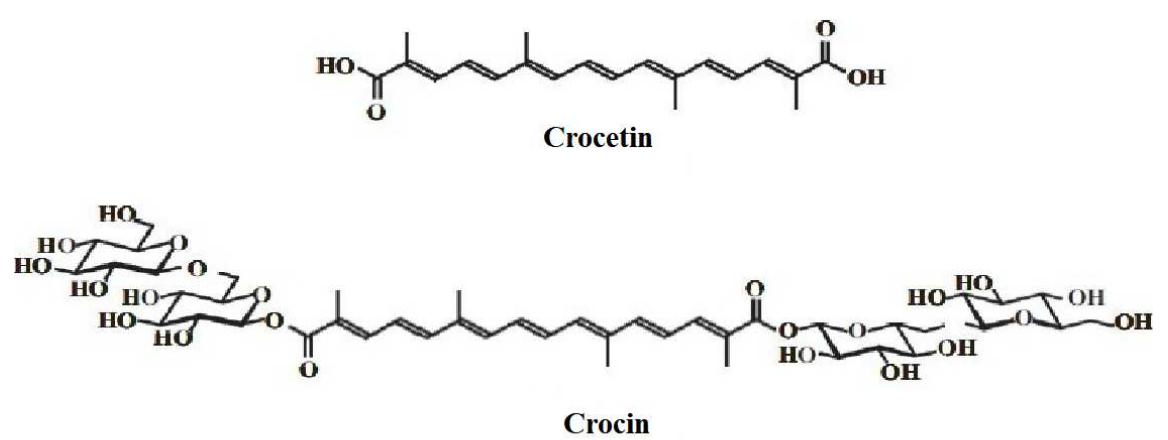

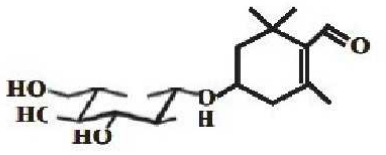

Picrocrocin

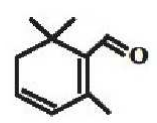

Safranal

Figure 2. Main bioactive compounds of saffron (Jan et al., 2014)

The most influential chemical compounds in the coloring power of saffron are crocins. Crocins are unusual water-soluble carotenoids. In comparison to other carotenoids, crocins have a wider application as a colorant in food and medicine, mainly because of their high solubility (Moghaddasi, 2010). Despite crocins, saffron also contains some more trans and cis isomers of crocetin. In plant kingdom crocins are derived from enzymatic oxidative cleavage of the carotenoid zeaxanthin, which is broken down at both ends and produces crocetin dialdehyde and picrocrocin (Fig. 3). Precursor of safranal is picrocrocin. Transformation take place during dehydration because of temperature or activity of enzyme glycosidase. Depending of way of transformation safranal can be 
produced directly from picrocrocin or via HTCC (4-hydroxy-2,6,6-trimethyl-1-cyclohexene-1carboxaldehyde) (Velasco-Negueruela, 2001; Tong et al., 2015).

On the other hand, crocetin dialdehyde is oxidized and esterified by different glucosyl transferases to generate the crocetin esters. Carmona et al., 2006 suggested that crocetin esters could also be precursor of safranal, and can be converted to safranal by an enzymatic action or drying at high temperature. In this possible pathway, TDOI (4,5,6,7-tetrahydro-7,7-dimethyl-5-oxo-3Hisobenzofuranone) is an important intermediate compound (Carmona et al., 2006; Tong et al., 2015).

The difference in the type of sugar moieties placed in the positions $\mathrm{R} 1$ and $\mathrm{R} 2$ results in the six classes of crocins including: crocin 1 , crocin 2 , crocin 20 , crocin 3 , crocin 4 , and crocin 5 . In that context, glycosyl and gentiobiosyl moieties along with $\mathrm{H}$ are present in $\mathrm{R} 1$ and $\mathrm{R} 2$ at different patterns, making various types of crocins. Regarding isomeric structure of crocins occurring in saffron, both isomeric structures of cis and trans are present in saffron (Tong et al., 2015).

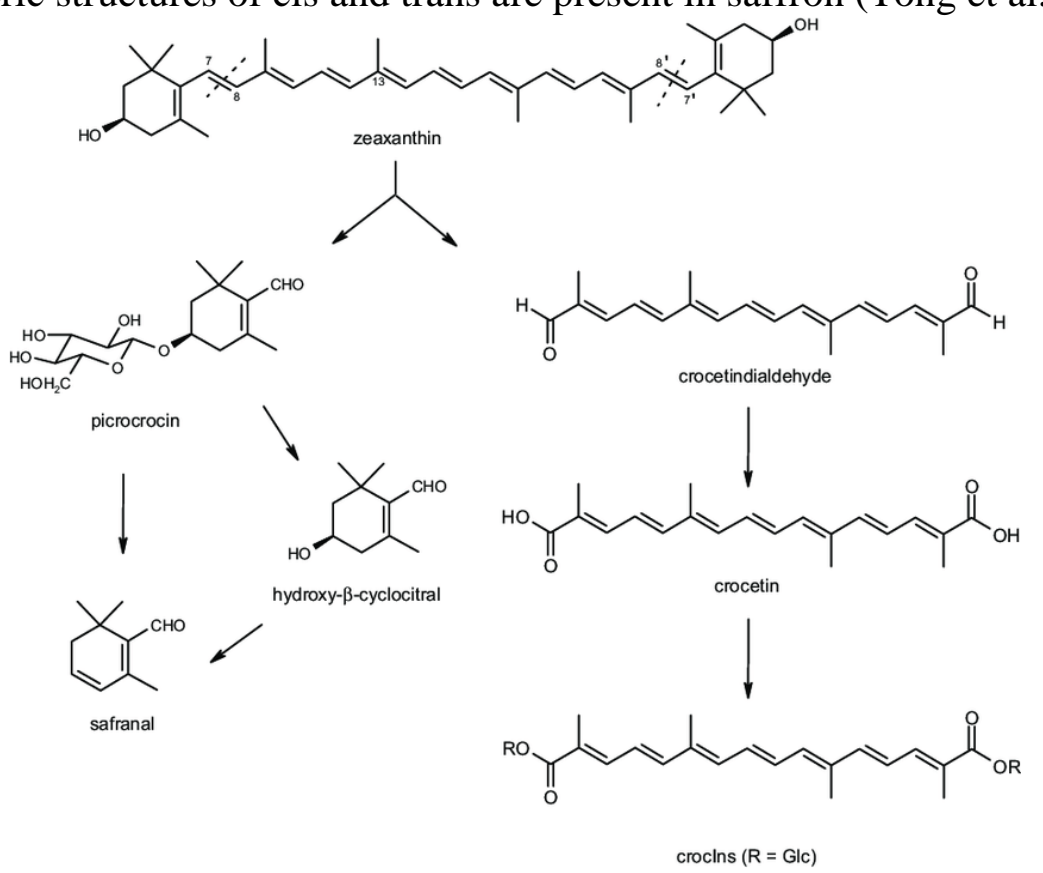

Figure 3. Possible pathways for the generation of the main compounds in saffron (Gresta et al., 2008)

Quality of saffron is highly influenced by the presence of its three major compounds (crocin, picrocrocin, and saffranal). The main parameter in deciding the quality of saffron is its coloring potential which can be measured by the quantity of its colorant components (Moghaddasi, 2010). Many methods of analyzing saffron components have been described. The quality of saffron is regulated by ISO 3632 standard, aimed at standardizing the classification of saffron worldwide (Mzabri et al., 2019).

\section{EFFECTS OF AGROLOGICAL AND ENVIRONMENTAL FACTORS ON QUALITY OF SAFFRON}

Agrologically, ecophysiologically, and phenologically, saffron is different from most agronomic crops. Saffron grows from corm, a nutrient reserve organ that supports all flower nutrient requirements in the first year of production (Kafi et al., 2006). 
This plant prefers friable, loose, low-density, well-watered, and well-drained soils. Soil conditions for saffron production should be evaluated in the context of corm establishment, growth, and propagation. It can be grown on soils varying from sandy to well-drained clay loams. Saffron also has an unusual reverse biological cycle. It blooms in autumn (October to November) and spends a long period of dormancy in the summer. It is adaptable to temperate and sub-tropical climates (Gresta et al., 2008).

Environmental factors such as: physical and chemical properties of the soil, climatic conditions, time of harvesting the flowers, age of the corm have influence on size of flower and stigma inside it. Besides, climate and soil characteristics, planting time, planting depth, corm size/weight, crop density, nutrient management, weed management, growth regulators, harvest, and post-harvest management also have influence on saffron quality and quantity (Mounira and Cantrell, 2009).

Saffron production does not require much water, but timeliness of irrigation, particularly the first irrigation is very important for flowering emergence and length of flowering period. There are many agrological factors contributing to yield and quality of saffron such as: corm size, method of planting, irrigation application, irrigation interval and recent practice of summer irrigation which is not usual practice for saffron (Koocheki et al., 2007).

As is reported in the literature environmental conditions have an effect on anatomy and secondary metabolites of plants. High altitude and low temperature have been proven that have positive effect on the production of secondary metabolites. Low temperature is a crucial factor for flowering emergence. An increase in the content of phenol compounds and carotenoids with rising altitude has been postulated as a response to increasing UV-radiation. Also it has been assumed that biosynthesis of carotenoids is influenced by environmental conditions such as temperature. The quantity of carotenoids increases as temperature decreases. Moreover, amount of saffron secondary metabolites depends of age of corm (younger saffron samples have higher content than older ones). The reason of this could be: reduction in corm size, closing of corm to soil surface, low accessibility to mineral elements or reduced enzymatic activity in older corms (; Zidon et al., 2005; Schonhof et al., 2006; Zarinkamar et al 2011).

\section{EFFECTS OF POSTHARVEST PROCESSING ON SAFFRON BIOACTIVE COMPOUNDS}

Postharvest processing plays a crucial role in the quality characteristics of saffron. Postharvest processing, such as drying methods and storage conditions, determines the stability of saffron, which directly affects the market value of the product. The draying process is most important postharvest treatment which is necessary to convert $C$. sativus stigmas into saffron spice. Drying brings about the physical, biochemical, and chemical changes, which are necessary to achieve the desired attributes of saffron. It is a critical step in development of the principal substance responsible for saffron's aroma, safranal. Also draying process plays an important role in preserving the spice (Tong et al., 2015).

Moisture content in saffron is a critical parameter for preservation of its characteristics. Drying operations are necessary for production of a high-quality product that has the highest level of color and flavor. During the dehydration process, the stigmas lose about $80 \%$ of their weight. Generally, during the drying process the moisture content of stigmas decreases between $8 \%$ and $10 \%$. A lower moisture content, at least below $12 \%$, maintains the quality of saffron for a longer time (VelascoNegueruela et al., 2001; Carmona et al., 2005; Koocheki, 2020). 
The drying process not only plays an important role in the preservation of saffron, but also it is a critical step in development of the principal substance responsible for saffron's aroma, safranal. Fresh stigmas are not able to impart their organoleptic characteristics to food. A drying process brings about the physical, biochemical, and chemical changes necessary to achieve the desired attributes of saffron (Carmona et al., 2005).

This process is aimed to protect the crocins by stopping the enzymatic reactions responsible for its biodegradation, which can be achieved with temperatures above $60^{\circ} \mathrm{C}$ for the minimum possible time. Selecting the most appropriate drying method is one of the important steps in postharvest processing in order to prepare saffron stigmas with the highest amount of crocins, and at the same time to maintain the best morphological characteristics (Aghaei et al., 2019).

The drying process differs from country to country. There are two ways to dehydrate saffron in terms of temperature. One process is carried out at room temperature directly under sunlight or in air-ventilated conditions, as is done in India, Morocco, and Iran. It takes place outdoors, and the product is directly exposed to sunlight. Under sunlight carotenoids in saffron can be degraded or isomerized. The second drying process is carried out at higher temperatures by using hot air or any other heating source. This is the process used in Spain, Greece, and Italy (Carmona et al., 2005).

Carmona et al., 2007 noted that if saffron with the highest coloring strength is desired, it is better to submit it to a higher temperature at lower times than to lower temperature at longer processing time. The saffron dried at room temperature possess far less quantity of safranal. Safranal precursors are formed during the dehydration process. Safranal starts to be formed from its precursors at the temperature between 70 and $90{ }^{\circ} \mathrm{C}$. From a chemical point of view, differences between the samples dehydrated at low and high temperatures, under sunlight or in shade, can be explained as photochemical degradation, or isomerization of the carotenoids responsible for saffron color (Carmona et al., 2005).

The quantities of crocins, safranal, and picrocrocin in saffron depend mainly on the method used for drying the stigmas. In traditional methods using solar and air drying, the carotenoids in saffron can be degraded. However, the purplish red. color and aroma in saffron are retained when the air drying method is used. In drying over charcoal or using any other heating source, the organoleptic qualities and its purplish red color are preserved.

\section{CONCLUSIONS}

There are several crucial steps in saffron processing, from flowers harvesting to drying of stigmas. Quality characteristics of saffron are directly affected by the postharvest processing stages. The drying process plays a crucial role in the quality characteristics of saffron and its physicochemical properties and determine the and economical value of the saffron.

\section{REFERENCES}

Abdullaev, F.I., Frenkel, G.D. (1999). Saffron in biological and medical research. In: M. Negbi, eds,. Saffron, Crocus sativus L. Amsterdam: Harwood Academic Publisher, Amsterdam, 103-113.

Abdullaev, F. (2007). Biological properties and medicinal use of saffron (Crocus Sativus L.). Acta Hort. (ISHS), 739, 339-345.

Aghaei, Z., Jafari, S.M., Dehnad, D. (2019). Effect of different drying methods on the physicochemical properties and bioactive components of saffron powder. Plant Foods Human Nutr, 74, 171-178.

Bathaie, Z.S., Mousavi, Z (2010). New applications and mechanisms of action of saffron and its important ingredients. Critical Reviews in Food Science and Nutrition, 50, 761-786. 


\section{Current Trends in Natural Sciences}

Vol. 9, Issue 17, pp. 289-295, 2020

https://doi.org/10.47068/ctns.2020.v9i17.036

Current Trends in Natural Sciences (on-line)

ISSN: 2284-953X

Current Trends in Natural Sciences (CD-Rom)

ISSN: 2284-9521

ISSN-L: 2284-9521 ISSN-L: 2284-9521

Bagur, M.J., Salinas, G.L.A., Jiménez-Monreal, A.M., Chaouqi, S., Llorens, S., Martínez-Tomé, M., Alonso, G.L. (2018). Saffron: An old medicinal plant and a potential novel functional food. Molecules, 23, 30, 1-21. doi:10.3390/molecules23010030

Caballero-Ortega, H., Pereda-Miranda, R., Riverón-Negrete, L., Hernández, J.M, Mayra Medécigo-Ríos, M., CastilloVillanueva, A., Abdullaev, F.I (2004). Chemical composition of saffron (Crocus sativus L.) from four countries. Acta Hort, 650, ISHS 2004, 321-326.

Carmona, M., Zalacain, A., Pardo, J.E., Alvarruiz, A., Alonso, G.L. (2005). Influence of different drying and aging conditions on saffron constituents. J. Agric. Food Chem, 53, 3974-3979.

Carmona, M., Zalacain, A., Salinas, M.R., Alonso, G. L. (2006). Generation of saffron volatiles by thermal carotenoid degradation. Journal of Agricultural and Food Chemistry, 54 (18), 6825-6834.

Carmona, M., Zalacain, A., Salinas, M.R., Alonso, G.L. (2007). A new approach to saffron aroma. Critical Reviews in Food Science and Nutrition, 47 (2), 145-159.

Gresta, F., Lombardo, G.M., Siracusa, L., Ruberto, G. (2008). Saffron, an alternative crop for sustainable agricultural systems. A review. Agron. Sustain. Dev, 28, 95-112.

Husaini, A.M., Wani, S.A., Sofi, P., Rather, A.G., Parray, G.A., Shikari, A.B., Mir, J.I. (2009). Bioinformatics for saffron (Crocus sativus L.) improvement. Communications in Biometry and Crop Science, 4 (1), 3-8.

ISO/TS 3632-1/2 (2003). Technical specifications. Saffron (Crocus sativus L.). Part 1 (Specification) and Part 2 (Test methods). The International Organization for Standarization: Geneve, Switzerland

Jan, S., Wani A..A, Kamili, A.N., Kashtwari, M (2014). Distribution, chemical composition and medicinal importance of saffron (Crocus sativus L.). African Journal of Plant Scienes, Vol. 8(12), 537-545.

Kafi, M., Koocheki, A., Rashed-Mohassel, M.H., Nassiri, M., (2006). Saffron, Production and Processing. Science Publishers, New Hampshire, USA.

Koocheki, A., Nassiri, M., Behdani, M.A (2007). Agronomic attributes of saffron yield at agroecosystems scale. Iran. Acta Hort. (ISHS), 739, $33-40$.

Koocheki, A. (2020). Dehydration of saffron stigmas In A. Koocheki, M. Khajen-Hosseini, eds, Saffron: Science, Technology and Health. Woodhead Publishing Series in Food Science, Technology and Nutrition, Elsevier. 291298.

Moghaddasi, S. M. (2010). Saffron chemicals and medicine usage. Journal of Medicinal Plants Research, 4(6), 427430.

Mounira, L., Cantrell, C. (2009). Quantification of saffron (Crocus sativus L.) metabolites crocins, picrocrocin and safranal for quality determination of the spice grown under different environmental Moroccan conditions. Scientia Horticulturae, 121, 366-373.

Mzabri, I., Addi, M., Abdelbasset Berrichi, A. (2019). Traditional and modern uses of saffron (Crocus Sativus). Cosmetics, 6 (63), 1-11.

Rahimi, M (2015). Chemical and medicinal properties of saffron. Bull. Env.Pharmacol. Life Sci, 4(3), 69-81.

Schonhof, I., Klaring, H., Krumbein, A., Chuben, W., Schrerer, M. (2006). Effect of temperature increase under radiation condition on phytochemicals and ascorbic acid in greenhouse grown broccoli. Agriculture, Ecosystems and Environment, (119), 103-111.

Srivastava, R., Ahmed, H., Dixit, R.K., Dharamveer, Saraf S.A. (2010). Crocus sativus L.: A comprehensive review. Pharmacogn Rev, 4(8), 200-208.

Tong, Y., Zhu, X, Yan, Y., Liu, R., Gong, F., Zhang, L., Hu, J., Fang, L., Wang, R, Wang, P. (2015). The influence of different drying methods on constituents and antioxidant activity of saffron from China. International Journal of Analytical Chemistry, 2015 (1), 1-8. http://dx.doi.org/10.1155/2015/953164

Velasco-Negueruela, A. (2001). Saffron. In Handbook of herbs and spices, CRC Press LLC, 276-288.

Wani, B. A., Hamza, A.K.R. Mohiddin, F.A. (2011). Saffron: A repository of medicinal properties. Journal of Medicinal Plants Research, 5(11), 2131-2135.

Zarinkamar, F., Tajik, S., Soleimanpour, S. (2011). Effects of altitude on anatomy and concentration of crocin, picrocrocin and safranal in Crocus sativus L. Australian Journal of Crop Science, 831-838.

Zidorn, C., Schubert, B., Stuppner, H. (2005). Altitudinal differences in the contents of phenolics in flowering heads of three members of the tribe Lactuceae (Asteraceae) occurring as introduced species in New Zealand. Biochemical Systematics and Ecology, 33. 855-872.

https://rainbowpeacockco.wordpress.com/on-saffron (retrieved, May, 2020) 